\section{ORDINARY CITIES: BETWEEN MODERNITY AND DEVELOPMENT}

Jennifer Robinson

New York: Routledge, 2006

Vera F. Rezende

Professora do Programa de Pós-graduação em

Arquitetura e Urbanismo da UFF

Todas as cidades são comuns, complexas e div ersas. Este é o argumento que J ennifer Robinson constrói ao longo de seu livı, apontando questôes com vistas à r enovação da teoria urbana. A crítica central de seu trabalho se orienta para um cor te criado pelos estudos urbanos com a divisão das cidades em termos de um gr upo, pertencente ao Primeiro Mundo, cidadessede da inovação e de iniciativas modernizantes, e um outro grupo dentro de um quadr o de desenvolvimento, no qual estariam destinadas à comparação (e, se possível, à reação), em busca de se tornarem modernas em algum nível.

A visão de um mundo urbano hierarquizado própria dessa postura teórica estaria impedindo o campo dos estudos urbanos de r econhecer inovação e criação em cidades antecipadamente enquadradas na tradição ou em situações de atraso . A consequência dessa percepção ainda colonialista, segundo $\mathrm{R}$ obinson, seria a aceitação de que o mundo desenvolvido possui a capacidade de criação, enquanto ao outro mundo restaria a de imitação.

Mais do que criar categorias de cidades per tencentes ao Ocidente, ao Terceiro Mundo, da África, da América do $S$ ul, pós-socialistas ou hierar quias como desenvolvidas ou em desenv olvimento, mundiais ou globais, a autora nos acena com um univ erso de cidades diversas, dinâmicas e passíveis de vida econômica e social. Além disso, ao negar que somente algumas cidades sejam capazes de gerar iniciativas no campo do urbanismo, essa abordagem busca encontrar um mundo de formas urbanas ou urbanizaçōes fr uto da criati vidade e inventividade dos habitantes. Sua argumentação é construída na medida em que coloca em evidência cidades como Rio de J aneiro, Joanesburgo, Lusaka e Kuala L umpur, com o objetiv o de traz er situaçóes que exemplifiquem um mundo de cidades comuns.
O primeiro movimento necessário para Robinson seria reinterpretar modernismo e modernidade, e reconhecê-los como possív eis manifestações em qualquer cidade, nas "ordinary cities", que dão título a seu livro. Se ser moderno é ser contemporâneo, aderir à mudança e ao dinamismo é uma condição pr esente em qualquer sociedade em transformação.

A sua argumentação é construída a partir de dois eixos (modernidade e desenv olvimento), por per cebêlos como conceitos que dividem a abordagem usual da teoria urbana em Ocidente e outras cidades. Para a autora, modernidade, amplamente definida no início do século XX, seria a autocaracterização do $\mathrm{O}$ cidente, colocando-se em relação aos "outros" e aos "outros lugares". São esses conceitos que atribuiriam dinamismo e inovação, isto é, modernidade a algumas cidades, enquanto imporiam às demais uma busca por modernização, através de iniciativ as de desenv olvimento para alcançá-las. Segundo Robinson, essas noçóes têm sido centrais na análise da vida urbana, e unidas, trabalham no sentido de limitar tanto as imagens da vida nas ci dades quanto as práticas de planejamento possív eis.

$\mathrm{Na}$ sociologia urbana do início do séculoXX, continua a autora, estev e presente a noção de moderni dade através de autores-chave para a teoria urbana, que no rastro de práticas coloniais estudaram cidades consideradas criativas, dinâmicas e modernas. A pesar da crítica produzida principalmente no período de 1940 a 1970, as tendências iniciais foram $r$ etomadas com o avanço de teorias que tentaram explicar situações de globalização. Como resultado, vários estudos se fixa ram em categorias de sucesso, as ricas cidades globais, e categorias de futuro sombrio, as megacidades.

A autora busca reformular o conceito de moder nidade e deslocá-lo do Ocidente para aplicá-lo a qualquer cidade, assim como pr etende um $r$ eenquadramento do desenv olvimento de cidades como um conjunto de desafios que se coloca tanto para as mais ricas quanto para as mais pobr es. Rejeita, entretanto, as visões de modernidade alternativ a ou que plurali zam a experiência de modernidade por entender que continuam a considerá-la a partir do Ocidente.

No primeiro capítulo, a autora coloca em discussão alguns teóricos da Escola de Chicago, mostrando como a noção de experiência urbana é colocada em contraste com a tradição, e como são constr uídos desde o início do século XX os fundamentos da corr ente 
teoria urbana, traduzidos em um moderno " aqui" e "agora" em contraposição a um tradicional "lá" e " então". Inspira-se em Walter Benjamin para refutar uma teoria do progresso, em que ev entos se apresentam de forma sequencial em um tempo v azio, trazendo como alternativa uma visão dialética da modernidade e da tradição como conceitos copresentes e interdependentes. O segundo capítulo explora debates já efetuados em torno das ideias da Escola de Chicago, mas traz vitalidade para a discussão com o grupo de antropólogos "africanistas" (a "Escola de Manchester"), reforçando o argumento da impossibilidade de uma teoria urbana de caráter universal.

O terceiro capítulo aler ta para a necessidade de se repensar o Ocidente como fonte da modernidade, e discute a afirmação de que em algumas cidades o conceito de moderno ger ou formas ar quitetônicas e urbanas autênticas, enquanto em outras se deu um processo de mimetização. A autora traz para o debate as cidades de $\mathrm{N}$ ova York, Rio de J aneiro e $\mathrm{K}$ uala Lumpur e as manifestações do moderno na ar quitetura. Afirma que o estilo internacional da ar quitetura de Nova York tomou por empréstimo experiências de outros países e, ainda assim, a cidade foi considerada geradora de inventividade. A arquitetura brasileira das décadas de 1930 e 1940, acr escenta, foi r econhecida como autêntica e inovadora - vide o Pavilhão na Feira de Nova York em 1939, a Exposição no Museu de Arte Moderna na mesma cidade e o livio Brazil Builds em 1943. A pesar de v alorizada a par tir dessa época por sua criatividade ao combinar características mo dernas, nacionais e $r$ egionais, destaca $\mathrm{R}$ obinson, ela foi vista como "fora do lugar" e dependente de sua influência europeia.

Com o entendimento de que no decorr er do século XX a crescente conexão do comércio e da comunicação em termos mundiais dominaram os estudos urbanos, o quarto capítulo propõe uma reterritorialização desses estudos em dir eção às cidades comuns. I ronicamente, segundo a autora, mesmo quando o trans nacionalismo é visto como uma característica das experiências urbanas, as cidades são hierar quicamente ordenadas com efeitos danosos, tanto para as ricas quanto para as pobres.

Enquanto inúmer os estudos enfatizam cidades globais ou mundiais, flux os ou $\mathrm{r}$ edes, o Capítulo 5 reafirma a impossibilidade de se pensar cidades em termos genéricos, e estabelece a necessidade de pensálas sob um recorte transversal no que se refere à diversidade e à complexidade. A ambição aqui é privilegiar estratégias que pr omovam inter vençôes criativ as ou destaquem a distinção pr esente em cada cidade, livrando as mais pobres de um urbanismo como imitação de experiências ou como tentativ a de aproximarse das mais ricas.

Como conclusão, o livr o ensaia estratégias que o campo dos estudos urbanos, sob o risco de se tornar irrelevante, deve perseguir na constr ução da teoria e da prática (de caráter pós-colonial), em $\mathrm{r}$ esposta a um mundo de cidades em expansão habitadas por uma população pobre. A autora $r$ econhece que estudiosos e formuladores de políticas em vários países têm desen volvido trabalhos que tratam da multiplicidade de espacialidades e da diversidade de suas cidades.

Reconhece, ainda, existir uma abertura no campo da teoria social que $v$ aloriza a pr odução de conhecimento de outr os lugares, e que $r$ epensa fundamentos de seu próprio conhecimento . Mas a visão estrita, segundo ela, provocou perdas não facilmente corrigidas. A solução traduz-se num engajamento cosmopolita por parte de estudiosos, ou seja, o compr ometimento com a pr odução de conhecimento em outr os locais, adotando " cosmopolitanismos div ergentes" ( "discrepant cosmopolitanisms"), expressão tomada por empréstimo de J ames Clifford (1997), com a qual a autora pretende definir um tipo de abor dagem cosmopolita, que não seja homogênea nem univ ersalista.

As r eflexôes trazidas pelo livr o se traduz em em questóes sobre como proceder para dar seguimento a esses novos estudos urbanos e sobre quais seriam as políticas adequadas para essas cidades comuns. Respostas difíceis, nos adianta $\mathrm{R}$ obinson: " pode-se lev ar uma vida para conhecer um local, mas, muito mais árduo é construir análises para um conjunto de cidades e diferentes contextos". (p.167) Assumir que todas as cidades são comuns ("ordinary"), reconhece a autora, é apenas um começo para se pensar um mundo de cidades.

O livro de Robinson dá continuidade às discussões propostas por seu ar tigo anterior "Global and world cities: a view from off the map" (2002), enriquece o debate e interessa a estudiosos da teoria urbana e do planejamento urbano, revolvendo as bases das noçôes de desenvolvimento e de modernidade. Sem propor um modelo para os estudos urbanos, afirma prin- 
cípios e pr oduz um aler ta contra armadilhas conceituais, que ofuscam a difícil compreensão do conjunto de cidades e que dão lugar, perigosamente, a práticas, políticas e pr opostas univ ersalistas. A argumentação da autora tem fortes implicações para futuros estudos, ampliando as opções por linhas de pesquisa e v alorizando a reflexão sobre contextos diversos em diferentes países. P oderíamos diz er, tal qual $\mathrm{R}$ obinson, em "qualquer" país.

\section{REFERÊNCIAS BIBLIOGRÁFICAS}

CLIFFORD, J. (1997) Routes: Travel and Translation in the late Twentieth Century. Cambridge, Mass.: H arvard University Press.

ROBINSON, J. (2002) Global and world cities: a vie w from off the map . International J ournal of $R$ egional Research. 26:531-54.

\section{QUESTÕES TERRITORIAIS NA AMÉRICA LATINA}

Amalia Inés Geraiges de Lemos, M aría Laura Silveira, Mónica Arroyo (orgs.)

Buenos Aires: CLACSO; São Paulo: USP, 2006

Rebeca Scherer

USP

Esta obra, oportuna e necessária, traz na abertura o texto inédito da conferência proferida pelo geógrafo Milton S antos em 1996 por ocasião do Congr esso SOLAR, e reúne, em continuação, os trabalhos do X EGAL - Encontro de G eógrafos da América Latina, realizado em São Paulo em março de 2005. I nspirado na história vivida nas últimas décadas, o Encontro propõe que se caminhe "D o labirinto da solidão ao espaço da solidariedade". Desde o Prefácio, elaborado pelas compiladoras dos trabalhos e organizadoras do Encontro, Amalia Inés Geraiges de Lemos, M aría Laura Silveira e Mónica Arr oyo, são explicitadas duas posições fundamentais para dar conta das $r$ esponsabilidades de todos nós, geógrafos ou não: assumir nossa condição de produtores do saber, e fazê-lo sem r ecusar o olhar estrangeiro, porém, de forma intransigente a par tir da perspectiv a latino-americana, trazida pelo estudo responsável e consciente de seu espaço, $\mathrm{v}$ ale dizer, de sua sociedade.

"Por Uma Epistemologia Existencial" é o título da conferência de Milton Santos. Não cabe resenhá-la, apenas relatar que analisa diferentes modelos de interpretação que ao longo do século XX se constr uíram sobre a América Latina denunciando o enfoque economicista, que pr evaleceu durante longo período e que resultou em versões reducionistas da realidade existente. Milton reafirma a necessidade fundamental da ela boração de uma epistemologia que inclua obrigatoriamente o espaço, na medida em que, " a sociedade é apenas o ser; o existir é coisa do espaço " e ainda "o tempo é pr oduzido pelo lugar e por aqueles que nele estão" (p.25).

O texto de Milton Santos é seguido da conferência r ealizada pela geógrafa Amalia I nés $G$ eraiges de Lemos, na sessão de aber tura do EGAL: "América Latina: à Procura de Uma Geografia Mestiça". Nela, a Professora reconstrói o caminho per corrido e o caminho que julga necessário percorrer na busca do que classifica, também ela, como uma geografia mestiça, pois mestiça, e via de r egra, inadequadamente analisada, é nossa formação social.

Apoiada numa bibliografia consistente e imune ao "canto das sereias do poder" (Milton Santos, José de Souza M artins, S erge G ruzinski, E dgar M orin, Boaventura de S ousa Santos, Michel Serres, Nestor Canclini, E mílio Tenti F anfani, entr e outr os), per corre com brilho os conceitos fundamentais dessas contri buições e convoca os colegas para o pleno ex ercício de uma contemporaneidade militante.

O livro divide-se em três par tes, a saber: Passado, Presente e D esafios Teóricos, seguida de D inâmicas Territoriais Contemporâneas e, finalmente, U ma Geografia Para a Saúde. Contempla - sempre do ponto de vista da geografia, tomando como referência empírica a América Latina, e dentr o de uma abor dagem histórica e interdisciplinar - temas complex os co mo: a relação entre as finanças e a vulnerabilidade dos territórios; a formação de blocos de nações e as especificidades do Mercosul; os efeitos da globalização e do neoliberalis mo sobr e Sociedades e Estados; os determinantes e condições para a formação da consciência na América Latina; a produção social da saúde; a afirmação da territorialidade estatal; discursos e imaginários políticos na organização de nações; a ocupação da Amazônia; o in- 